Palate-Amongst the 200 cases included in this inquiry, $>2$ possessed palates inordinately arched, and with this increased arching were noticed various abnormalities. In some the palate was unsymmetrical, the two sides having different degrees of concavity, or one side plane, and the other concave. In 34 the palates were excessively arched, approximating to the appearance of the roof of a house, and, with this extreme angularity, was great narrowness. Excessive arching of the palate occurred, therefore, in 58 per cent. Fixcessive flattening of the palate was observed in 4 cases. In 34 cases, or 17 per cent., the palate had a very prominent antero $p$ sterior ridge or keel, corresponding to the line of approximation of the palatal bones. In 7 the palate bones did not meet, leaving a sulcus between them, the mucous membrane being, however, continuous. There was no instance of the ordinary cleft palate, and I may remark that in an examination of nearly 600 illiots, I have failed in meeting with an example of that deformity. In several the hard palate extended but a short distance posteriorly, from defect of the palatal process of the superior maxillary bone and entire absence of the palatal process of the palate bone, and in all these cases the velum palati was unusually flaccid. In the majority of cases there was marked narrowness of the palate. The following table represents the measure. ments in 24 ths of an inch of the space between the posterior bicuspid teeth of opposite sides:-

\begin{tabular}{|c|c|c|c|c|c|c|c|c|c|}
\hline No. & $\begin{array}{l}\text { Distance. } \\
\text { In. }\end{array}$ & & No. & & $\begin{array}{l}\text { istance. } \\
\text { In. }\end{array}$ & & No. & & $\begin{array}{l}\text { Distanc } \\
\text { In. }\end{array}$ \\
\hline 2 & at $\frac{16}{34}$ & $\cdots$ & 11 & at & $\frac{23}{24}$ & $\ldots$ & 13 & at & $1_{\frac{5}{24}}^{5}$ \\
\hline 1 & $2, \frac{18}{24}$ & $\ldots$ & 24 & ," & 1 & $\ldots$ & 9 & , & $1_{\frac{8}{2 \pi}}$ \\
\hline 3 & $\frac{19}{24}$ & $\ldots$ & 37 & , & $1 \frac{1}{24}$ & $\ldots$ & 1 & , & $1_{24}^{7}$ \\
\hline 2 & $\frac{20}{24}$ & $\ldots$ & 25 & , & $1 \frac{2}{2 x}$ & $\ldots$ & 5 & , & $1 \frac{8}{24}$ \\
\hline 15 & $\frac{21}{24}$ & $\ldots$ & 23 & $"$ & $1 \frac{3}{24}$ & $\ldots$ & 3 & , & $1 \frac{12}{24}$ \\
\hline 1 &,$\quad \frac{22}{2}$ & $\ldots$ & 17 & ,, & $1 \frac{4}{24}$ & $\ldots$ & 1 & ,, & $1 \frac{2}{2} \frac{2}{4}$ \\
\hline
\end{tabular}

It will be observed that 33 per cent. do not exceed 1 inch, and that 62 per cent., while being more than 1 inch, do not exceed $1 \frac{1}{4}$ inch; whereas the normal average has been stated to be $1 \frac{1}{9}$ inch. It is worthy of notice that these numbers hold no direct relation to the age or stature of the patients examined. Thus, in a youth 22 years of age and $6 \mathrm{ft} .1$ in. in height, so narrow is the palate that there is ouly $1_{\frac{2}{2}}^{2}$ inch between the bicuspids, and only $\frac{10}{2}$ inch between the opposite gums at their widest interval. The lowest measurements occurred in a boy and girl, the boy 12 and the girl 13 years of age. Neither is there a dir ct relation between the width of the palate and the cranial capacity; for in a microcephal, whose palate was 22 inch wide the internal canthi of the eyes were $\frac{23}{34}$ inch distant from one another; while in a macrocephal whose palate was $\frac{33}{24}$ inch wide, the distance between the internal canthi amounted to 2 inches.

Teeth. - The principal characteristics of the teeth in idiots are, that the period of the first dentition is delayed, the second dentition considerably postponed, and that they undergo very general and rapid decay. In many cases the anterior surface of the incisors presents a honeycombed appearance, but in no one instance have I observed those special characters which have been well shown by Mr. Hutchinson to be significant of congenital syphilis. In a large number of cases they are developed irregularly, are crowded, and the canine occupy a dif ferent plane from the other teeth, - all these irregularities resulting from the imperfect development of the superior maxillary bone. In 6 cases, or 3 per cent., the upper incisors projected to such an extreme degree as to produce grave deformity. In 7 cases the teeth of the lower jaw were in advance of those of the upper.

Tonque. - The most prevailing character noticeable in the tongue of idiots is the hypertrophy of the fungiform papille Undue prominence of the papillæ was observed in 101 instances. In several there is a marked want of co-ordination in the move ments of the tongue, so that the patient, although endeavouring to comply with the request, is unable to protrude it. This condition is usually associated with an absence of general coordinated movements, and in the improvement which is effected by treatment it is usually the most persistent derangement of motility. In 16 cases the tongue presented a soldened appear. ance, and exhibited deep transverse furrows on its dorsil surface; in all these patients one is able to trace a marked physiological and psychological agreement, and so much do they resemble one another in these respects that they might readily be taken for members of the same family. Inordinate size occurred in 12 instances, and in almost every case was associated with defective power of articulation. In 2 the tongue was unusually long. 33 were mute; 16 semi.mute. In 83 the speech was indistinct. In 62 the speech was fair. Stammering was observed in 4

Tonsils. - One cause of the peculiar speech prevailing among idiots is the condition of the tonsils. These observations for the most part were made in the summer, when the tonsils were not likely to be rendered worse than their usual condition by climatic influences. In 30 instances they were injected, in 17 slightly enlarged, in 79 considerably enlarged, and in 5 so much increased in size as to interfere with deglutition and respiration.

Mucous membrane, dec.-Besides the injection of the mucous membrane of the tonsils which has been noticed, other regions of the oral cavity are liable to this condition. The velum palati, uvula, and pillars of the pharynx were found to be thus characterized in 27 instances. The posterior wall of the pha. rynx was observed to be marked by considerable vascular injection in 33 cases, and in 6 the mucous membrane had assumed a granular appearance. The buccal and labial glands were generally hypeltrophied, and the salivary glands were frequently enlarged. In 11 instances the sublingual gland was greatly enlarged. The uvula was elongated in 14 cases, bifid in 2 , very short in 1 , and entirely absent in 1 . The lips were hypertrophied in 2 . In 1 case only were the gums noticed to be swollen and tumid, a circumstance arising probably from the abundant supply of fresh vegetables with which the patients are provided.

Slavering. - The flow of saliva from the mouth is universally associated in the popular mind with the condition of idiocy. The slavering may vary in degree. It may occur only at periods of excitement, and at meal times, or with scarcely any intermission thronghout the day, producing in severe cases excoriation of the chin. Amongst 325 cases which I have examined, I find 72 , or 22 per cent., in which this habit was noticed. Of these, 28 slaver to a slight extent, 17 rath $t r$ more so, and 26 in an aggravated degree. This peculiarity depends, I believe, on two or three causes - 1st, the increased secretion of saliva; $2 \mathrm{nd}$, the deformed conclition of the mouth; 3rd, the want of co.ordinated movements in the muscles of the tongue; and 4th, the absence of tonicity in the labial muscles. Seeing that slavering exists in 22 per cent. of imbeciles, the question may arise-Is it confined to this section of the community? I am not prepared to say that it is never associated with mental vigour; but I believe that, excluding childhood, old age, disease of the mouth and neural lesions, slavering is very rarely unconnected with mental imbecility. Moreover, I have examined with reference to this question 1000 persons, who are doing the everyday work of the world, without meeting with a single example.

Summary. - We have thus seen that idiocy is not simply a cerebral lesion; that it carries with it marked physical deviations, of which $I$ have shown conspicuous examples in the mouth; narrowed, arched, and unsymmetrical palates; tardily developed, irregular, and rapidly decaying teeth; a hyperæmic condition of the mucous membrane and glands; elongated uvulas and hypertrophied tousils; large, ennervated, and rugous tongues, deficient in co-ordinated movements and in their special function; saliva secreted inordinately, and retained in. continently. Such are some of the characteristics of a class, in which mental vigour is in abeyance, which should be taken in connexion with the psychological state in diagnosis, and inculcate the doctrine, that the psychical condition of these unfortunates should be specially sought to be ameliorated by an improvement of their physical condition.

Earlswood, Redhill, Jan. 1862.

\section{EPITHEIIAL CANCER ON THE TONGUE SUCCESSFULLY REMOVED BY EXCISION.}

By I. WILLIAMS, M.D., Bracknell.

Tue following case, which may be worthy of record in the pages of THe LANCET, occurred in my practice lately:-

John $\mathrm{H}-$, a single man, aged fifty, applied to me suffering from a sore-throat, as he supposed, and felt as if he could not live through the night from suffocation. On examination, I found a large fleshy mass attached to the posterior part of the tongue, and extending quite into the larynx, which had slightly commenced ulcerating. I at once concluded that this must be "epithelioma."

From this man's previons history I found that he had felt as if something had been attached to the tongue, that he had had 
a difficulty in swallowing for the last four months, and that his father had died of cancer. As the urgency of the case demanded instant relief, [ at once removed it, with but little hæmorrhage occurring, which was soon stopped by means of nitrate of silver.

The poor fellow, after the operation, felt so gratified that he almost danced for joy. The mass was about an inch and a half long, and half an inch wide. It consisted of tesselated cells, or like scaly epithelium. I ordered him three grains of iodide of iron, three times a day, one pint of bitter ale, some beeftea, and a little wine.

The man has gone on well ever since, and the cicatrix is quite healed up. I expect the disease will return; butit is some gratification to prolong life even for a short time. Most authors say cancer destroys life in four years from the first commencement, and more rapidly when it occurs on the tongue. $I$ intend watching this case carefully, and will make the result known in a future number of THE LANCET.

Berks, Jan. 1862.

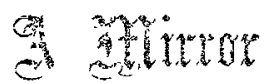

OF THE PRAOTIC 0 F

\section{MEDICINE AND SURGERY IV THE}

\section{HOSPITALS OF LONDON.}

Nulla est alia pro certo noscendi via, nisi quam plurimas et morboram et dissection!m historias, tam aliorum proprias, collectas habcre et inter se comparare.-Mosqa.M. De Sed. et Cans. Morb., lib, 14. Procmium.

\section{CHARING-CROSS HOSPITAL.}

CHRONIC PERITONITIS, WITH PURULENT EFFUSION, PARACENTESIS ON TWO OCCASI $I N S$; EXTREME

LOWNESS OF THE PATIENT; RECOVERY.

(Under the care of Dr. WIILSHTE.)

Chronic peritonitis is acknowledged to be a very unpromising disease in regard to treatment, and usually the efforts of the physician are confined to a mitigation of the symptoms or retardation of the progress of the malady. A cure is rarely brought about, more es pecially when the effusion has reached the suppurative stage. During the past summer, however, a most unfavourable case of this kind-one in which life seemed hanging in the balance for several weeks - came under our observation, but which ended in a good recovery from the means perseveringly employed to save life. There can be no doubt that, in this instance, the intestines and their peritoneal investments have become adherent; yet, with such a disadvantage, it is probable that the patient may enjoy a fair share of health in a country district.

For the notes of the case we are indebted to Mr. T. C. Wigg, late physician's assistant to the hospital:-

Ann M-, aged twenty four, a housemaid, living in London, admitted March 12th, 1561. She states that she has always enjoyed good health until about two years since, when she first noticed a swelling of the stomach, which gradually increased up to the present time. She cannot assign any cause for the complaint; she is not aware of having caught cold nor of having had liver or heart affection. She has had a cough in the wirter for the last two or three years. The catamenia had always been regular.

Upon examination, the abdomen is found uniformly distended by fluid. She measures thirty five inches and $a$ half in circum. ference. The bowels are constipated; the tongue is clean; the countenance has an anxious look, and the patient is rather emaciated. There is not any cedema of the lower limbs, nor can any particular disease of the heart, lungs, or kidneys be detected. She was ordered blue-pill and squill with the acetate of potash in decoction of broomtops three times a day, and an ointment of mercury and iodine to be rubbed over the belly. Compound jalap powder was taken occasionally, as an aperient. This kind of treatment was continued from the 12 th until the 27th March, when, the circumference of the abdomen being reduced only one inch, and the patient complaining of dyspnea and pain of the left side, and having vomited some blood, Dr. Willshire requested Mr. Canton to perform the operation of paracentesis abdominis. Accordingly, on the day last named, 240 ounces of clear serum were drawn off, after which a full dose of opium was ordered to be given.

For some days after the operation the case was an anxious one, vomiting, pain, and depression being prominent. These symptoms were met by opium, stimulauts, and effervescing draughts containing prussic acid, under which the patient rallied. In a short time, however, the abdomen became of the same size as before.

As the patient was beginning to be worn out by the continual pain from distension and by broken rest, Dr. Willshire decided upon having the abdomen again punctured. Accordingly, on the $20 \mathrm{th}$ of April, Mr. Canton performed the operation, and gave exit to 232 ounces of sero purulent fluid, which, when flowing, was so dense and deeply coloured as to look like pure pus. After the operation, a full dose of opium and eight ounces of wine were ordered.

For some weeks following great fears were entertained for the safety of the patient. Pain, want of rest, vomiting, and diarrhcea were the nore urgent symptoms. The emaciation, too, became extreme. A small abscess formed in one of the labia, and twice a little matter collected at the seat of the last puncture of the abdomen. It was believed that some purulent matter was passed per anum, but this was uncertain. The appetite of ihe patient became exceedingly capricious, and her temper extremely trying to the nurses and the patients near her. Opium in one or other of its forms, but chiefly "black drop," along with alkalies and cffervescing draughts, and a good supporting diet, constituted, in general terms, the regimen to which she was subjected. At this juncture a troublesome cough made its appearance, followed by muco-purulent expectoration. This, together with the extreme capillary development over the forehead, arms, back, and indeed over the body generally, and the peculiar form of peritonitis from which the patient had suffered, gave rise to some fears that pulmonary taberculosis would prove fatal to her. But physicat examination certainly did not warrant the assumption. Fortunately, the cough gradually ceased, the abdomen did not again enlarge, and the patient began to pick up a little flesh; her countenance, also, assumed, if not a cheerful, yet a less anxious expression. Improvement still continued, when she was discharged (having an order for Walton-upon. Thames) August 12th, 1-61.

\section{ST. GEORGE'S HOSPITAL.}

CHRONIC PERITONITIS WITH EFFUSION, ENCYSTED BY ADHESTONS; DISEASE OF THE LIVER AND HEART; FATAL RESULT; AUTOPSY.

(Under the care of Dr. Pitman.)

THE details of the present case are of not less interest than those of the foregoing, for although there were no active symptoms of peritoneal inflammation on the patient's admission, nevertheless the autopsy afforded sufficient evidence that it had been at one time very extensive, and had given rise to the adhesions which existed. An encysted cavity filled with fluid was firmly attached to the liver; and it is worthy of remark that, considerable as was the ascites during life, no fluid was found in the cavity of the peritoneum after death. For the notes of the case we are indebted to Dr. W. H. Dickinson, late medical registrar to the hospital.

John C_- aged thirty-five, admitted Sept. 11th, 1861. Four or five years ago he suffered from ascites and anasarca, from which he perfectly recovered, except that his legs remained cdematous. As an hotel waiter, he had indulged in tippling-principally wine, and not spirits; frequently drinking when too much occupied to eat. Two months before admission the cedema of his legs increased, and he then perceived that his belly was becoming enlarged. Both these symptoms continued to advance, until at length he became enormonsly distended, the skin in many places being blistered and filled with fluid. His face was sallow, and his conjunctivæe tinged with bile; his bowels open, and pulse feeble. His liver could be felt extending downwards into the abdomen. There was a loud systolic murmur, but the urine was passed quite clear; it was acid, and free from albumen. He was ordered morphine every night; this he continued to take until Sept. 18th, when a grain of opium was substituted for it, in consequence of the itching 